\title{
Serosurvey of Leptospira spp. and Toxoplasma gondii in rats captured from two zoos in Southern Brazil
}

\author{
Maysa Pellizzaro ${ }^{[1]}$, Francisco de Oliveira Conrado ${ }^{[2]}$, Camila Marinelli Martins ${ }^{[3]}$, \\ Sâmea Fernandes Joaquim ${ }^{[1]}$, Fernando Ferreira ${ }^{[3]}$, Helio Langoni ${ }^{[4]}$ \\ and Alexander Welker Biondo ${ }^{[5]}$
}

\begin{abstract}
[1]. Programa de Pós-Graduação em Medicina Veterinária, Faculdade de Medicina Veterinária e Zootecnia, Universidade Estadual Paulista, Botucatu, SP, Brasil. [2]. Programa de Pós-graduação em Biologia Celular, Universidade Federal do Paraná, Curitiba, PR, Brasil. [3]. Departamento de Medicina Veterinária Preventiva e Saúde Animal, Faculdade de Medicina Veterinária e Zootecnia, Universidade de São Paulo, São Paulo, SP, Brasil. [4]. Departamento de Higiene Veterinária e Saúde Pública, Faculdade de Medicina Veterinária e Zootecnia, Universidade Estadual Paulista, Botucatu, SP, Brasil. [5]. Departamento de Medicina Veterinária, Universidade Federal do Paraná, Curitiba, PR, Brasil.
\end{abstract}

\begin{abstract}
Introduction: Norway rats (Rattus norvegicus) are zoonotic reservoirs for Leptospira spp. and Toxoplasma gondii, and influence diseases in urban areas. Methods: Free-ranging and laboratory-raised rats from two zoos in southern Brazil were tested for Leptospira spp. and T. gondii using microscopic agglutination and modified agglutination tests, respectively. Results: Overall, $25.6 \%$ and $4.6 \%$ free-ranging rats tested positive for Leptospira spp. and T. gondii, respectively, with co-seropositivity occurring in two animals. For laboratory-raised rats, $20 \%$ tested positive for Leptospira spp. Also, Leptospira biflexa serovar Patoc and Leptospira noguchii serovar Panama were found. Conclusions: Serosurveys can show the environmental prevalence of zoonotic pathogens.
\end{abstract}

Keywords: Norway rat. Leptospirosis. Toxoplasmosis.

Leptospirosis is a worldwide zoonosis associated with urban slums in low-to-middle income areas in developing countries, such as Brazil ${ }^{1,2}$. The disease is caused by spirochetes of the genus Leptospira, which infect a wide range of hosts ${ }^{1,3}$. Rats (Rattus norvegicus, Rattus rattus) are the main reservoirs of leptospirosis and they remain asymptomatic whilst viable Leptospira spp. organisms are released in their urine ${ }^{3}$. Released spirochetes may contaminate water, food ${ }^{1}$, and soil, which become potential sources of Leptospira spp. infection, although the risk to humans depends upon contact with the hosts ${ }^{4}$.

Toxoplasmosis is caused by Toxoplasma gondii, a ubiquitous protozoan with a worldwide distribution ${ }^{5}$. Rodents are intermediate hosts for $T$. gondii, as they are preyed upon by infected felids, which are the definitive hosts ${ }^{5}$. Rats can also indicate T. gondii contamination and the risk of infection for definitive hosts ${ }^{6}$.

Despite the risk of free-ranging rats in zoos to zoo personnel, visitors, and captive wildlife animals, no study has focused on these environments in urban areas. Accordingly, this study aimed to determine the seroprevalence of Leptospira spp. and T. gondii in free-ranging and laboratory-raised rats in Curitiba, Brazil.

Corresponding author: Dr. Alexander Welker Biondo e-mail: abiondo@ufpr.br

Received 5 April 2017

Accepted 24 August 2017
Curitiba is the capital of Paraná State and Brazil's ninth most populous city $(1,893,997$ inhabitants), with the country's third best human development index $(0.823)^{7}$. Two city conservation areas were chosen for sampling. First, the current Curitiba City Zoo $\left(589,000 \mathrm{~m}^{2}\right)$, which is $17 \mathrm{~km}$ from the city center area and houses a collection of more than 2,000 animals. Second, the former zoo, housed in a smaller, central public park in a downtown area known as the Public Promenade $\left(69,285 \mathrm{~m}^{2}\right)$, which houses 300 captive animals.

Targeted trapping by zoo personnel is routinely used for rodent control. The study population derived from this control strategy and included rats trapped from July 2013 to January 2014. Rat capture was performed using live overnight traps baited with fruits and raw corn. Traps containing animals were placed inside a sealed plastic container and isoflurane was infused via an oxygen machine. Sedation was achieved using an inhalation mask, and blood was collected by intracardiac venipuncture into dry vacuum tubes. After sampling, animals were euthanized using a lethal intracardiac dose of potassium chloride. Serum was separated by centrifuging and stored at $-80^{\circ} \mathrm{C}$ until analysis.

Species (Rattus norvegicus or Rattus Rattus), sex (male and female), weight (rats $<200 \mathrm{~g}$ were juveniles, and those $>200 \mathrm{~g}$ were adults), and trap location (City Zoo, Public Promenade, or nursery) were recorded. Laboratory-raised rats from a nursery 
facility within the park were used as negative controls. Because older rats are generally heavier, age was estimated based on body weight ${ }^{2,8}$.

A microscopic agglutination test (MAT) was performed for serological diagnosis of Leptospira spp. exposure, according to the World Organization for Animal Health guidelines ${ }^{9}$. The panel of pathogenic and saprophytic strains used to determine the serology titers was composed of 20 serogroups and 30 serovars. The serovars (australis, bratislava, autumnalis, butembo, castellonis, bataviae, canicola, whitcombi, cynopteri, djasiman, sentot, gryppotyphosa, hebdomadis, copenhageni, icterohaemorrhagiae, javanica, panama, pomona, pyrogenes, hardjo prajitno, hardjo miniswajezak, hardjo, hardjo c.t.g., hardjo bovis, wolffi, shermani, tarassovi, andamana, patoc, and guaricura) were maintained and replicated weekly in Ellinghausen-McCullough-Johnson-Harris media (EMJH) (Difco Laboratories ${ }^{\circledR}$, Detroit, Michigan, USA) at $28^{\circ} \mathrm{C}$, in aerobic conditions. These serovars were initially provided by the Bacterial Zoonosis Laboratory (University of São Paulo), and maintained at the NUPEZO laboratory (São Paulo State University). Sera were diluted using phosphate buffered saline (PBS) (pH 7.6), mixed individually with each serovar suspension at 1:1, making the final serum dilution 1:100 in the screening test, and incubated at $28^{\circ} \mathrm{C}$ for $1 \mathrm{~h}$. Pure PBS (pH 7.6) solution was used as a negative control. The analysis was performed under dark field microscopy (Carl Zeiss ${ }^{\circledR}$, Oberkochen, BadenWürttemberg, Germany) with $100 \times$ magnification. For the MAT cut-off value, titers equal to or higher than 100 were considered positive ${ }^{9,10}$. Positive samples were further diluted to their final titer, and tested only to the reacted serovar. If more than one serovar showed reactivity, the highest titer was assumed as the most probable causative agent of the infection. Cases positive for more than one serovar and with equally strong titers were described as co-infections ${ }^{1,9}$.

A modified agglutination test was used to detect $T$. gondiispecific immunoglobulin $\mathrm{G}$ (IgG) antibodies. Samples were considered positive upon reaching a cut-off titer of 25 or higher, as previously established ${ }^{11}$.

The frequency of samples testing positive for $T$. gondii and Leptospira spp. (and their respective serovars) was analyzed and compared by age and sex using a Chi-square test. Weight was tested using the D' Agostino test for a normal distribution (package $f$ Basics in the $\mathrm{R}$ environment). Mean weights were compared between positive and negative samples using Student's t-test and one-way analysis of variance (ANOVA) was used for sampling location. Results were considered statistically significant at $\mathrm{p}<0.05$. Statistical analyses were performed using Statistical Package for the Social Sciences (SPSS) software (SPSS Inc. Released 2008. SPSS Statistics for Windows, Version 17.0. Chicago: SPSS Inc.).

A total of 63 blood samples was obtained: 43 free-ranging trapped rats (23 from the Public Promenade and 20 from Curitiba Zoo), and 20 laboratory-raised rats from the nursery. All animals were classified as Rattus norvegicus. Females accounted for $30 / 63(47.6 \%)$ of all rats.

The overall frequency of Leptospira spp. was 11/43 (25.6\%) in captured rats and $4 / 20(20 \%)$ in laboratory-raised rats. Nine different serovars were detected (Table 1), the most frequent being serovar patoc $(5 / 11: 45.5 \%)$, followed by copenhageni (4/11: 36.4\%), and icterohaemorrhagiae (3/11: 27.3\%). Six rats showed cross-reactivity: two with serovars icterohaemorrhagiae, copenhageni, and patoc; one with panama and patoc; one with sentot and patoc; one with sentot and djasiman; and one with djasiman and patoc. The frequency of rats seropositive for Leptospira spp. in relation to sex and sampling location is shown in Table 2.

The frequency of seropositive rats in both zoos was lower than that previously described in Baltimore $(32 \%)^{12}$, Copenhagen $(94 \%)^{8}$, and Salvador $(63.1 \%)^{13}$. This unexpected outcome might be explained by the limited sample size in this study. In this species, presence of serum titer does not indicate

TABLE 1: Microscopic agglutination test (MAT) results by serovar and title.

\begin{tabular}{lcc}
\hline Serovars & Number & Title \\
\hline Copenhageni & 4 & $(400,400,200,200)$ \\
Icterohaemorrhagiae & 3 & $(100,100,100)$ \\
Patoc & 7 & $(200,200,100,100,100,100,100)$ \\
Panama & 1 & $(1,600)$ \\
Sentot & 1 & $(100)$ \\
Djasiman & 3 & $(200,100,100)$ \\
Castellonis & 1 & $(100)$ \\
Hardjo-minis & 1 & $(200)$ \\
Andamana & 1 & $(100)$ \\
\hline Total & $22^{*}$ & -
\end{tabular}

${ }^{*}$ Considering cross-reactivity. 
TABLE 2: Frequency distribution of Leptospira spp. serology of rats in relation to sex, age, and sampling location.

\begin{tabular}{|c|c|c|c|c|c|c|}
\hline & \multicolumn{6}{|c|}{ Leptospira spp. } \\
\hline & & \multicolumn{3}{|c|}{ Positive } & \multirow[t]{2}{*}{ Total } & \multirow[t]{2}{*}{ Negative } \\
\hline & & $\begin{array}{c}\text { Public Prom- } \\
\text { enade (n) }\end{array}$ & City Zoo (n) & $\begin{array}{c}\text { Laboratory-raised } \\
\text { nursery }(n)\end{array}$ & & \\
\hline \multirow[t]{2}{*}{ Sex } & Females & 4 & 4 & 1 & $9 / 30$ & $21 / 30$ \\
\hline & Males & 3 & 0 & 3 & $6 / 33$ & $27 / 33$ \\
\hline \multirow[t]{2}{*}{ Age } & Juveniles & 3 & 0 & 0 & $3 / 23$ & $20 / 23$ \\
\hline & Adults & 4 & 4 & 4 & $12 / 40$ & $28 / 40$ \\
\hline
\end{tabular}

No statistical significance $(p>0.05)$ was observed in all variables.

that no bacteria were released in the urine ${ }^{2}$, as usually occurs in susceptible hosts. A limitation of our study was that we did not assess the kidney colonization of rats to determine their true prevalence and potential for spreading viable Leptospira spp. in the environment.

The relatively high frequency of the patoc serovar in this study was unexpected. This serovar is part of the Semaranga serogroup, and is described as a saprophytic strain (L. biflexa, serovar patoc). Notably, it is implicated in cross-reactions in human serologic studies ${ }^{9}$. Nevertheless, the copenhageni and icterohaemorrhagiae serovars, both in the Icterohaemorrhagiae serogroup, have been previously described in rats, which are considered the major reservoirs of Leptospira spp. ${ }^{13}$.

There was no significant difference in Leptospira spp. seropositivity between sexes $(p=0.211)$ or sampling locations $(p=0.645)$. Although a higher prevalence in females was found in a previous study ${ }^{12}$, no such difference was expected, as the risk of exposure is similar for both sexes ${ }^{2,8,13}$.

Although the mean weight of seronegative rats was lower than seropositive rats $[223.65 \mathrm{~g} \pm$ standard deviation (SD) 125.38 versus $286.33 \pm \mathrm{SD} 93.36]$, this was not significant $(p=0.079)$. This result corroborates previous studies ${ }^{8,12}$, as older animals have a higher probability of infection from an increased chance of exposure ${ }^{8}$. In addition, no significant differences were found when evaluating the age stratification based on weight $(\mathrm{p}=0.191)($ Table 2).

Four laboratory-raised rats from the nursery were seropositive for Leptospira spp. The serovars were djasiman, patoc, and andamana. The lack of a sealed or strict enclosure room at the nursery may explain this, as synanthropic rats can access the facility. The highest titer obtained was to L. noguchii serovar panama $(1,600)$ in an animal captured at
Public Promenade, away from any livestock mammals that are the usual reservoirs for this strain ${ }^{14}$. To the best of our knowledge, there are no previous reports of infection with this serovar in rats.

The frequency of rats seropositive for $T$. gondii was consistent with previous studies, which reported a prevalence of $0.3 \%$ to $8 \%$ in other rodent species ${ }^{15,16}$. No significant differences between sexes were found in the frequency of $T$. gondii seropositive rats $(p=0.730)$ or sampling locations $(p=0.614)$ (Table 3).

The mean weight of seronegative rats was lower $(234.43 \mathrm{~g} \pm \mathrm{SD}$ 120.57) than that of seropositive rats $(365.00 \mathrm{~g} \pm \mathrm{SD} 21.21)$, but not significantly different $(\mathrm{p}=0.134)$. There was also no significant difference when evaluating age stratification based on weight $(\mathrm{p}=0.360)$ (Table 3). Seroprevalence may increase with age, as older animals are continuously exposed to contaminated environments.

Although the frequency of $T$. gondii was similar to that in previous studies, the role of rats in the lifecycle of this pathogen needs further investigation. Cats acquire the infection by hunting rats and birds 5 . However, a previous study with domiciled cats in Curitiba showed a seroprevalence of $16.3 \%$ for $T$. gondii, despite no association with hunting and/or outdoor access ${ }^{17}$. These results corroborate the low prevalence found in this study, indicating that rats may not be the main source of $T$. gondii infection in domestic cats.

Two captured rats showed co-infection with $T$. gondii and Leptospira spp. Although it is unlikely that Leptospira spp. infection caused immunosuppression and facilitated a secondary T. gondii infection, further investigations are needed to establish the cause of this co-infection. Moreover, if the immune system fails to recognize bacteria as a potential threat or risk of disease ${ }^{1}$, serology may not be the ideal diagnostic technique to detect active infection in rats.

TABLE 3: Frequency distribution of Toxoplasma gondii serology of rats in relation to sex, age, and sampling location.

\begin{tabular}{|c|c|c|c|c|c|c|}
\hline & \multicolumn{6}{|c|}{ Toxoplasma gondii } \\
\hline & & \multicolumn{3}{|c|}{ Positive } & \multirow[t]{2}{*}{ Total } & \multirow[t]{2}{*}{ Negative } \\
\hline & & Public Promenade (n) & City Zoo (n) & Laboratory-raised nursery ( $\mathrm{n}$ ) & & \\
\hline Sex & Females & 0 & 1 & 0 & $1 / 30$ & $29 / 30$ \\
\hline \multirow[t]{2}{*}{ Age } & Juveniles & 0 & 0 & 0 & $0 / 23$ & $23 / 23$ \\
\hline & Adults & 1 & 1 & 0 & $2 / 40$ & $38 / 40$ \\
\hline
\end{tabular}

No statistical significance $(p>0.05)$ was observed. 
In summary, a relatively low frequency of $T$. gondii and Leptospira spp. infection was observed in rats from two zoos in Curitiba. The serological status of other species such as dogs, cats, captive animals, and humans for these pathogens has been reported to be higher. However, the serological frequency indicated a high prevalence of Leptospira spp. in the zoos' synanthropic rat population. Future studies in Curitiba city should pinpoint the presence of these pathogens in rats and their importance as potential reservoirs. Finally, other diagnostic techniques should be included in surveillance studies for a better understanding of the role of free-ranging rats in spreading disease.

\section{Ethical considerations}

Capture and use of animals was approved by the Ethics Committee on Use of Animals of the Federal University of Paraná under protocol number CEUA/SCA (protocol number 057/2013). In addition, the study was approved by the city Secretary of Environment and officially included as part of the annual activities of the zoos.

\section{Conflict of interest}

The authors declare that there is no conflict of interest.

\section{REFERENCES}

1. Adler B. Leptospira and leptospirosis. $1^{\text {st }}$ edition. Springer-Verlag Berlin and Heidelberg; 2015. 293p.

2. Costa F, Wunder Jr.EA, De Oliveira D, Bisht V, Rodrigues G, Reis MG, et al. Patterns in Leptospira shedding in Norway rats (Rattus norvegicus) from Brazilian slum communities at high risk of disease transmission. PLoS Negl Trop Dis. 2015;9(6):e0003819.

3. Levett PN. Leptospirosis. Clin Microbiol Rev. 2001;14(2):296-326.

4. Hagan JE, Moraga P, Costa F, Capian N, Ribeiro GS, Wunder Jr $\mathrm{EA}$, et al. Spatiotemporal determinants of urban leptospirosis transmission: four-year prospective cohort study of slum residents in Brazil. PLoS Negl Trop Dis. 2016;10(1):e0004275.

5. Dubey JP, Frenkel JK. Toxoplasmosis of rats: a review, with considerations of their value as an animal model and their possible role in epidemiology. Vet Parasitol. 1998;77(1):1-32.

6. Ruffolo BB, Toledo RS, Martins FDC, Bugni FM, Costa L, Marana ERM, et al. Isolation and genotyping of Toxoplasma gondii in seronegative urban rats and presence of antibodies in communicating dogs in Brazil. Rev Inst Med Trop Sao Paulo. 2016;58:28.

7. Instituto Brasileiro de Geografia e Estatística. 2016 [cited 2016 dec 22] Available from: http://cidades.ibge.gov.br/v3/cidades/ municipio/4106902/

8. Krøjgaard LH, Villumsen S, Markussen MDK, Jensen JS, Leirs $\mathrm{H}$, Heiberg AC. High prevalence of Leptospira spp. in sewer rats (Rattus norvegicus). Epidemiol Infect. 2009;137(11):1586-92.

9. World Organisation for Animal Health (OIE). Manual of diagnostic tests and vaccines for terrestrial animals (mammals, birds and bees). Paris: Office International des Epizooties; 2014. 15p.

10. World Health Organization (WHO). Human leptospirosis: guidance for diagnosis, surveillance and control. WHO Library Cataloguingin-Publication Data; 2003. 122p.

11. Desmonts G, Remington JS. Direct agglutination test for diagnosis of Toxoplasma infection: method for increasing sensitivity and specificity. J Clin Microbiol. 1980;11(6)562-8.

12. Easterbrook JD, Kaplan JB, Vanasco NB, Reeves WK, Purcell $\mathrm{RH}$, Kosoy MY, et al. A survey of zoonotic pathogens carried by Norway Rats in Baltimore, Maryland, USA. Epidemiol Infect. 2007;135(7):1192-9.

13. Costa F, Porter FH, Rodrigues G, Farias H, de Faria MT, Wunder EA, et al. Infections by Leptospira interrogans, Seoul Virus, and Bartonella spp. among Norway rats (Rattus norvegicus) from the urban slum environment in Brazil. Vector Borne Zoonotic Dis. 2014;14(1):33-40.

14. Martins G, Loureiro AP, Hamond C, Pinna MH, Bremont S, Bourhy $\mathrm{P}$, et al. First isolation of Leptospira noguchii serogroups Panama and Autumnalis from cattle. Epidemiol Infect. 2015;143(7):1538-41.

15. Dubey JP, Bhaiyat MI, Macpherson CNL, Allie C, Chikweto A, Kwok OCH, et al. Prevalence of Toxoplasma gondii in Rats (Rattus norvegicus) in Grenada, West Indies. J Parasitol. 2006;92(5): $1107-8$.

16. Ayral F, Artois J, Zilber AL, Widén F, Pounder KC, Bicout DJ, et al. The relationship between socioeconomic indices and potentially zoonotic pathogens carried by wild Norway rats: a survey in Rhône, France (2010-2012). Epidemiol Infect. 2015;143(3):586-99.

17. Cruz MA, Ullmann LS, Montaño PY, Hoffmann JL, Langoni H, Biondo AW. Seroprevalence of Toxoplasma gondii infection in cats from Curitiba, Paraná, Brazil. Rev Bras Parasitol Vet 2011;20(3):256-8. 